\title{
TU/e EmonONEN

\section{A representation model for the solving time distribution of a set of design tasks in new product development (NPD)}

\section{Citation for published version (APA):}

Dragut, A. B., \& Bertrand, J. W. M. (2004). A representation model for the solving time distribution of a set of design tasks in new product development (NPD). (BETA publicatie : working papers; Vol. 125). Technische Universiteit Eindhoven.

\section{Document status and date:}

Published: 01/01/2004

\section{Document Version:}

Publisher's PDF, also known as Version of Record (includes final page, issue and volume numbers)

\section{Please check the document version of this publication:}

- A submitted manuscript is the version of the article upon submission and before peer-review. There can be important differences between the submitted version and the official published version of record. People interested in the research are advised to contact the author for the final version of the publication, or visit the $\mathrm{DOI}$ to the publisher's website.

- The final author version and the galley proof are versions of the publication after peer review.

- The final published version features the final layout of the paper including the volume, issue and page numbers.

Link to publication

\section{General rights}

Copyright and moral rights for the publications made accessible in the public portal are retained by the authors and/or other copyright owners and it is a condition of accessing publications that users recognise and abide by the legal requirements associated with these rights.

- Users may download and print one copy of any publication from the public portal for the purpose of private study or research.

- You may not further distribute the material or use it for any profit-making activity or commercial gain

- You may freely distribute the URL identifying the publication in the public portal.

If the publication is distributed under the terms of Article 25fa of the Dutch Copyright Act, indicated by the "Taverne" license above, please follow below link for the End User Agreement:

www.tue.nl/taverne

Take down policy

If you believe that this document breaches copyright please contact us at:

openaccess@tue.nl

providing details and we will investigate your claim. 


\title{
A representation model for the solving time distribution of a set of design tasks in New Product Development (NPD)
}

\author{
A. B. Dragut ${ }^{a}, *$ J. W. M. Bertrand ${ }^{\mathrm{b}}$

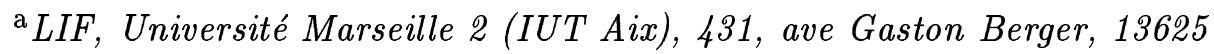 \\ Aix-en-Provence, France, and Eindhoven University of Technology, 5600MB \\ Eindhoven, The Netherlands \\ ${ }^{\mathrm{b}}$ Eindhoven University of Technology, 5600MB Eindhoven, The Netherlands
}

\begin{abstract}
Given the potential risks of new product development projects (NPD), the characteristics of the design tasks solving time distributions are critical for their effective management. In OR we need to find what operational characteristics of design tasks may delay projects. Other researchers already identified the technological novelty, the magnitude of the design tasks, the interactions between design tasks in an NPD project, and the balancing between projects among the most important causes of the unpredictability of the design tasks lead times in NPD projects.

We develop a simple queuing model incorporating all these four factors, to estimate the solving time distribution of the design tasks in NPD projects. Using the Kolmogorov-Smirnov goodness of fit test, we show the model to be no statistically significantly different from several sets of experimental data.

The model is a step towards mathematical control of NPD, and can be integrated in hierarchical planning and control solutions.
\end{abstract}

Key words: New Product Development, Queuing Models, Project Management

\section{Introduction}

In the field of New Product Development (NPD), project management and control receives much interest in both research and industrial communities.

\footnotetext{
* Corresponding author

Email address: dragut@allegro.iut.univ-aix.fr(A. B. Dragut).
} 
One of new product development main characteristics is the presence of various kinds of uncertainties, making its operational control quite a challenge nowadays. These uncertainties make it difficult to foresee the time at which the design tasks composing the NPD project will be completed, and appropriate control methods are very much needed. Several recent empirical and modelling studies have tried to better identify and classify possible causes of delays, and among them, Tatikonda and Rosenthal (2000) and van Oorschot (2001), enumerate the technological novelty, the magnitude of the design tasks, the interactions between the design tasks in the NPD project, and the balancing between projects as being the most important causes.

We present here a new mathematical model, based on queuing theory concepts, and incorporating all four causes of delay enumerated above. The main purpose of this model is to allow the computationally feasible estimation of the solving time distribution of design tasks in NPD projects.

Thus, this model is a step towards mathematical control of NPD, and it can, for instance, be integrated into a hierarchical control framework with multiple levels as in Dragut, (2004), as an intermediate and helper stage for setting the performance characteristics of the new product at the upper hierarchical level.

The contributions of this paper are the following:

- for the first time (to the best of our bibliographical knowledge) a mathematical model is derived for the solving time distribution of design tasks for NPD accounting for both design tasks technological uncertainties and human factor characteristics;

- the model is tested on real-life data for the case of one engineer, gradually showing the need of incorporating the various model elements;

- the mathematical model has implications for project management and for scheduling in NPD projects, by providing more accurate estimates for the solving time of the design tasks.

The remaining of the paper is organized as follows: in Section 2 we discuss the uncertainties inherent to NPD projects, leading to delays. In Section 3 we present the general setting of the model and the main parameters we wish to have in it. In Section 4 we formally describe the model and we show that its properties can be derived analytically from its parameters. In Section 5 we use eight sets of empirical data to validate the model through statistical analysis. We identify a constant difference between the model and the data sets, that can be attributed to the impact of the due date nearness on the amount of capacity allocated to a design task. Incorporating this factor in the model leads to a statistical good fit between the model and data. The conclusions are given in Section 6 . 


\section{Design tasks lead and solving times characteristics}

In literature NPD projects are generally described as consisting of a set of design tasks with precedence constraints. Uncertainty exists with respect to the amount of capacity needed to execute a design task, the interactions between design tasks and the set of design tasks that are needed to realize the design requirements. Much research has been done on how to structure an NPD project in order to minimize the interactions between design tasks and to maximize the concurrency of design tasks in a project (Eisenhardt and Tabrizi, 1995). In the planning planning and control of NPD projects, design tasks are allocated to engineers and the planning is based on estimates of the solving times and the lead times needed to complete the design tasks. We define the solving time as the amount of engineer capacity (in hours) needed to perform the design task, and the lead time as the time interval between the initiation and the completion of the process of solving a design task.

Recent empirical research on solving and lead time distributions of "discovery" tasks as the design tasks in NPD (McDermott (1999), Tatikonda and Rosenthal (2000), van Oorschot (2001)), and also the repair tasks in highly uncertain manufacturing systems (Innam (1999)) shows that

- the actual task lead time is almost never shorter than the planned lead time;

- the tasks are ill defined when planned (i.e. lax specification), and they usually turn out to contain unforeseen problems, thus requiring much more time than estimated;

- there exist technological interactions between the tasks even if they are planned for concurrent execution, which leads to a series of interruptions of the engineers while they are in the solving process of a design task (such as answering questions from the colleagues working on the same project as suggested by van Ooorschot(2001))

- the empirical probability density functions of the solving times and lead times of tasks are long-tailed and very skewed;

- the high rate of the introduction of new design tasks due to changes of functional specifications during the NPD project increases the lead times of the ones being solved.

The lead time distribution of design tasks might be influenced as well by the fact that when the due date of the design task is quite far in time, the engineers do not feel much pressure to work on it. This assumption is well supported by both cognitive psychology research (Gersick 1988, Buehler et al 1994, Seers and Woodruff 1997) and empirical NPD research (Oorschot (2001)). Seers and Woodruff (1997) discovered this effect of increased pressure by nearness of a deadline when they studied students working on academic tasks. At midpoint, instead of having $50 \%$ done, the results accounted only for approximately $10 \%$ 
of the total work that was needed. Thus, the majority of the work is performed in the second half of the lead time. The authors even found that progress follows an exponential function of time remaining, for relatively large a number of people (page 184). Moreover, these results correspond with the ones of Gersick (1988), who discovered a midpoint-transition, where progress makes a major jump from a small value. Van Oorschot (2001) in an empirical research of design tasks progress in lithographical equipment development found that up to the middle of the allotted lead time, little progress is made on the design tasks, and thereafter, progress steeply increases.

In the sequel we develop a mathematical model which gradually integrates these characteristics of the solving time distribution of NPD design tasks.

\section{The setting}

We denote by $M$ the number of engineers available to perform the work for the NPD project. This work is presented to them in units that we call design tasks, and that are the lowest level elements of what is called a work breakdown structure (WBS) of a project. This WBS is developed once the NPD initial system specifications are set, and, as in Aslaksen and Belcher (1992) and Shtub et al (1994), we consider it to be a product-oriented tree, starting with the complete product and progressing downwards through as many levels as necessary to obtain design elements that can be assigned to and performed by one of the engineers. The design tasks (elements of the lowest level) are always completely described by

- a task statement (what has to be accomplished),

- a detailed description of what the output or result of the work should be, and in what form is to be presented,

- an identification of the necessary prerequisites to start it.

At the upper levels of the management hierarchy, the design tasks are defined, placed in a network, and prioritized in a certain order. We assume the NPD project to have a finite number $N$ of initial tasks and that each design task has an Erlang-distributed solving time. The empirical research support for the last assumption is two-folded. First, according to a common assumption in system engineering (Aslaksen and Belcher (1992)), each design task $n$ is seen as being composed of $N_{a}(n)$ planned activities to be sequentially performed. Secondly, if we consider the solving time of the activities to be random variables independent identically exponentially distributed $\operatorname{Exp}(1 / \mu)$ (see for empirical evidence Best (1995), Reed (1998)), the analytical advantage of this view is that the solving time of a design task becomes indeed an $N_{a}(n)$ Erlang-distributed. Moreover, the split of each task into activities gives 


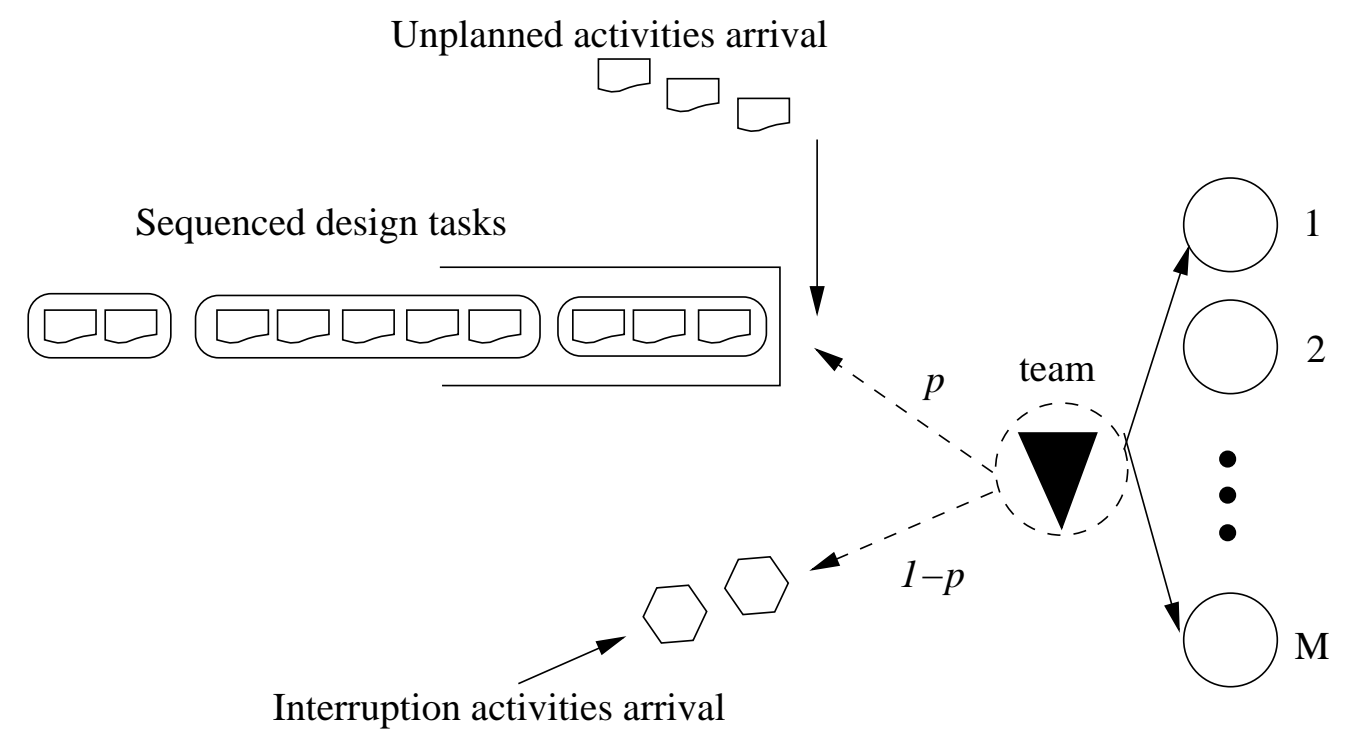

Fig. 1. The process diagram

a uniform measure of the magnitude of a design task (namely the number of activities involved).

Uncertainty regarding the solving time of a design task is modelled by assuming that in the ex-ante planning of the project for each design task is available only an estimate of its magnitude in terms of the number of activities involved.

\section{Model}

Based on the considerations of Section 2 regarding the causes of delays for design tasks in NPD projects, we further assume that for each unfinished design task, unplanned activities arrive according to a Poisson process of rate $\lambda(\lambda / \mu<M)$, due to the incapability to foresee at the outset all activities needed to complete the design task, so we model them to have preemptive resume priority over the planned activities. These unplanned activities have their solving time also exponentially distributed $\operatorname{Exp}(1 / \mu)$.

Moreover, even though the design tasks come already fully sequenced for each engineer, it may happen that some of them can in reality be performed in parallel, because the given order may only reflect some optimality criteria of the upper management hierarchy levels (a series of heuristic orderings can be found in Neumann and Zimmerman (1999)). Unlike machines, human beings are able to perceive the concurrency and the relative urgency of design tasks. Therefore, the decision of an engineer to work on specific design task or to allow for interruptions related to other concurrent design tasks is not really something that can be exactly modelled, due to the large variety of variables 
involved and due to the lack of detailed good quality empirical data to support theories. Namely, the data is in general collected per design task, and not per engineer, because it is very difficult to formally account for all the interactions between engineers during their work. Moreover, we assume that the interrptions due to technological interactions betwen the concurrent design tasks can be modelled as an activity with exponential distribution with mean $1 / \eta$. Thus, in our model, at any time instant the team will either work with the probability $p$ on the planned or unplanned activities of the design tasks in the order given by the scheduler, or, with a probability $1-p$, will spend time to other interruption activities. This is illustrated in the process diagram from Figure 1. The process diagram shows in detail how the united team works on the sequence design tasks (each composed of planned activities) as well as the unplanned activities arrival, all activitied being thus queued up for the engineers team.

We thus have the following notation:

- $M-$ the number of engineers

- $N$ - the number of design tasks

- $N_{a}(n)$ - the planned number of activities of design task $n$; for all $n$ from 1 to $N$;

- $\lambda$ - the Poisson process arrival rate of unplanned activities to the design task on work

- $\mu$ - the activity solving time exponential distribution parameter for each engineer

- $p$ - the probability that the team works on its design tasks, instead of allowing for interruptions (with probability $1-p$ ); obviously $p>0$.

- $\eta$ - the rate of the exponential solving time for the interruption activities;

The model makes use of queuing theory concepts and we show here how we can numerically compute the cumulative distribution function of the solving time. To this purpose, we state and prove the following.

Proposition 1 Let $\Xi$ be the random variable giving the solving time of the allocated design tasks, and $i$ the number of concurrent design tasks allocated to the engineers. Then for $i \geq 2$, $\Xi$ 's cumulative distribution function equals $F_{\Xi}(h)=\operatorname{Pr}\{\Xi \leq h\}=p \cdot \operatorname{Pr}\left\{C_{\max }(k) \leq h\right\}+(1-p) \cdot \operatorname{Pr}\left\{Y_{\text {Erlang }(i-1)} \leq h\right\}$, where $C_{\max }(k)$ is the makespan of a queueing system of $M$ parallel servers with a common queue having a series of $k=\sum_{n \in\{1, \ldots, N\}} N_{a}(n)$ of planned activities, and where $(1-p)$ is the probability that during the solving process the design tasks are interrupted for other activities. The planned activities have a common processing time, exponentially distributed with mean $\frac{1}{\mu}$, and their solving process is disturbed by a $\lambda$-Poisson arrival of unplanned activities. The arrival process of unplanned activities stops when all the planned activities are finished. Thus, the cumulative distribution function of $\Xi$ can be 
computed numerically.

Proof. All the planned activities are assumed to be independent identically distributed, and once the design tasks are ordered, we have as well an ordering among all the planned activities included in all the design tasks. The solving time of the planned activities already ordered is considered to be independent of the interruptions. However, this process creates extra work and will affect the completion time distribution of the entire set of design tasks. Thus, $\operatorname{Pr}\{\Xi \leq$ $h\}:=p \cdot \operatorname{Pr}\left\{C_{\max }(k) \leq h\right\}+(1-p) \cdot \operatorname{Pr}\left\{Y_{\text {Erlang }(i-1)} \leq h\right\}$. Now we have to prove that the Laplace-transform of the distribution function of $C_{\text {max }}(k)$ can be obtained, and inverted to complete our proof. Let $B P$ be the busy period in a $\mathrm{M} / \mathrm{M} / 1$ queue with arrival rate $\lambda$ and service rate $M \mu$. Then we have, for $k=M+q \geq M$

$$
C_{\max }(M+q)=B P+C_{\max }(M+q-1)
$$

and for $k<M$

$$
\begin{gathered}
C_{\max }(k)=Z(\Theta(k))+\left\{\begin{array}{c}
C_{\max }(k+1) \text { with probability } \frac{\lambda}{\Theta(k)} \\
C_{\max }(k-1) \text { with probability } \frac{k \mu}{\Theta(k)} \\
C_{\max }(0)
\end{array}\right.
\end{gathered}
$$

where $\Theta(k)=\lambda+k \mu$ and $Z$ is an exponential random variable. Let us consider the Laplace transform of $C_{\max }(k)$, and denote, for $s \geq 0$,

$$
\widehat{f}_{k}(s)=\Phi(k)(s)=E\left(\mathrm{e}^{-s C_{\max }(k)}\right)
$$

After computing it, the Laplace transform $\widehat{f}_{k}(s)$ can be inverted according to the Euler Inverse Laplace Transform method (Abate and Whitt (1995)). We have two cases, according to the value of $k$ with respect to $M$.

Case 1: $k=M+q \geq M$

$$
\Phi(k)(s)=\beta(s) \Phi(k-1)(s)=\ldots=\beta(s)^{k-M+1} \Phi(M-1)(s),
$$

where $\beta(s)$ is the Laplace-Stieltjes transform of the busy period $B P$. From Kleinrock (1975), we have that

$$
\beta(s)=\frac{\lambda+M \mu+s-\sqrt{(\lambda+M \mu+s)^{2}-4 \lambda M \mu}}{2 \lambda}
$$

So we shall only need to know how to compute $\Phi(M-1)(s)$. For that, we need the other case. 
Case 2: $k<M$

$$
\begin{aligned}
\Phi(k)(s) & =\frac{\Theta(k)}{\Theta(k)+s}\left(\frac{\lambda}{\Theta(k)} \Phi(k+1)(s)+\frac{k \mu}{\Theta(k)} \Phi(k-1)(s)\right) \\
& =\frac{\lambda}{\Theta(k)+s} \Phi(k+1)(s)+\frac{k \mu}{\Theta(k)+s} \Phi(k-1)(s) \\
\Phi(0)(s) & =1
\end{aligned}
$$

Now, on the border, we have the following:

$$
\begin{aligned}
\Phi(M-1)(s) & =\frac{\lambda}{\Theta(M-1)+s} \Phi(M)(s)+\frac{(M-1) \mu}{\Theta(M-1)+s} \Phi(M-2)(s) \\
\Phi(M)(s) & =\beta(s) \Phi(M-1)(s) \\
\Longrightarrow \Phi(M-1)(s) & =\frac{\lambda \beta(s)}{\Theta(M-1)+s} \Phi(M-1)(s)+\frac{(M-1) \mu}{\Theta(M-1)+s} \Phi(M-2)(s) \\
\Longrightarrow \Phi(M-1)(s) & =\frac{1}{1-\frac{\lambda \beta(s)}{\Theta(M-1)+s}} \cdot \frac{(M-1) \mu}{\Theta(M-1)+s} \Phi(M-2)(s) \\
\Longrightarrow \Phi(M-1)(s) & =\frac{(M-1) \mu}{\Theta(M-1)+s-\lambda \beta(s)} \Phi(M-2)(s)
\end{aligned}
$$

We want to have a relation linking the values of $\Phi(k)(s)$ either with respect to $\Phi(\cdot)(s)$ for greater values than $k$, or for smaller values, not both at the same time. Fix $s$ and denote by $\Phi_{k}=\Phi(k)(s)$, by $\alpha(k):=\frac{\lambda}{\Theta(k)+s}$ and by $\delta(k):=\frac{k \mu}{\Theta(k)+s}$. Then we can rewrite the recurrence of case $k<M$ as follows

$$
\Phi_{k}=\alpha(k) \cdot \Phi_{k+1}+\delta(k) \cdot \Phi_{k-1} .
$$

Because all $\Phi_{k}$ are positive, but not zero (because they are the result of an integral from a strictly positive function), we can also define $\gamma(k+1)=\frac{\Phi_{k+1}}{\Phi_{k}}$. Then we can rewrite the last equation as follows

$$
\Phi_{k}=\frac{\delta(k)}{1-\alpha(k) \cdot \gamma(k+1)} \Phi_{k-1}=\gamma(k) \cdot \Phi_{k-1}=\Phi_{0} \cdot \prod_{j=k}^{1} \gamma(j)=\prod_{j=k}^{1} \gamma(j)
$$

and for each $\gamma$ we have the recurrence relation

$$
\gamma(k)=\frac{\delta(k)}{1-\alpha(k) \cdot \gamma(k+1)}, \text { with } \gamma(M-1)=\frac{(M-1) \mu}{\Theta(M-1)+s-\lambda \beta(s)}
$$

This shows how to compute each of the $\Phi_{k}=\Phi(k)(s)$, for an arbitrary $s \geq 0$. Thus, we have completely solved the case $k<M$. 


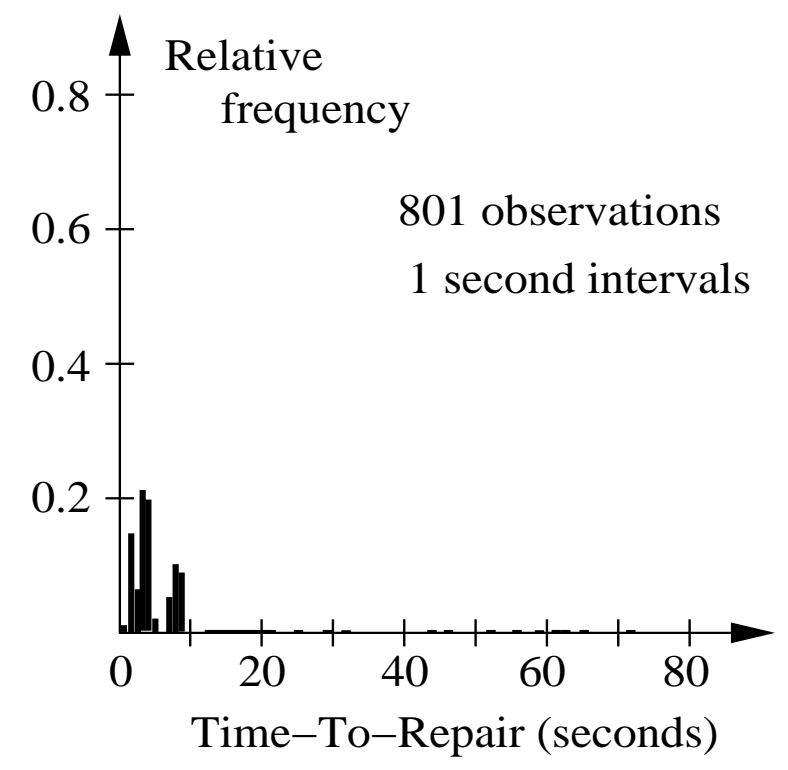

Fig. 2. B21's Time-To-Repair Histogram

In the next section we present the way we validated our model.

\section{Validation}

For the case of a team with more than one engineer, the shape of the distribution function given by this model is confirmed by the data collected in the experimental research of Innam (1999), which suggest a long tailed, skewed distribution function (see Figures 2, 3 and 4 ). The data collected does not refer to NPD design tasks, but to uncertain repair tasks, which can be considered to be very similar from a "discovery" point of view.

For the case of one engineer we have used the Kolmogorov-Smirnov goodness of fit test to show that the frequency diagrams of the real-life data sets of Oorschot (2001) are consistent with our model predicted cumulative distribution function. The Kolmogorov-Smirnov test finds the greatest discrepancy between the empirical and expected theoretical cumulative distribution functions, which is called the "D-statistic". We compared this against the critical D-statistic for that sample size.

In an empirical study van Oorschot (2001) collected data from engineers and from project leaders of a firm designing, producing and servicing advanced micro-lithography systems. On the average, there were allocated two to three design tasks per engineer to the team. As soon as the design task was known or planned, the engineers themselves estimated the lead time of a design task as the remaining solving time of the design tasks sequenced in before plus the solving time of the current one and a time slack of one day according 


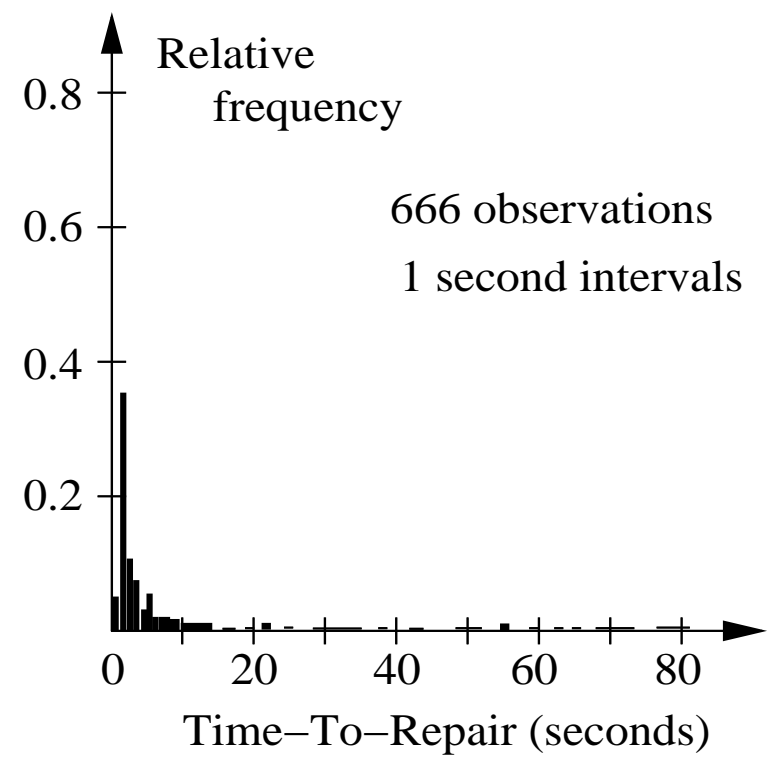

Fig. 3. B45's Time-To-Repair Histogram

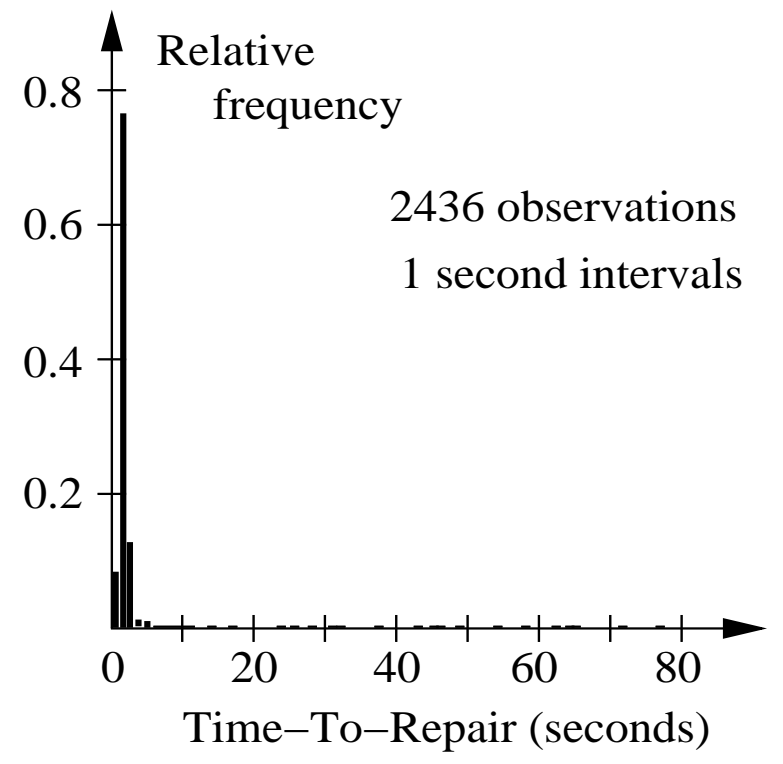

Fig. 4. B6's Time-To-Repair Histogram

to the rule of thumb in the company. Data were collected on the estimated and realized lead time of 424 design tasks with estimated lead time ranging from one to eight weeks. The design tasks were grouped according to estimated lead time. We computed the empirical distribution of the realized lead time for each group(see Figures 5, 6, 7 and 8). These data frequency diagrams showed some similarity with gamma-type probability density functions as well, but this hypothesis was rejected by a goodness of fit test at $\alpha=0.01$ in Oorschot et al (2002).

To test our model we have proceeded in a number of steps, first looking at 

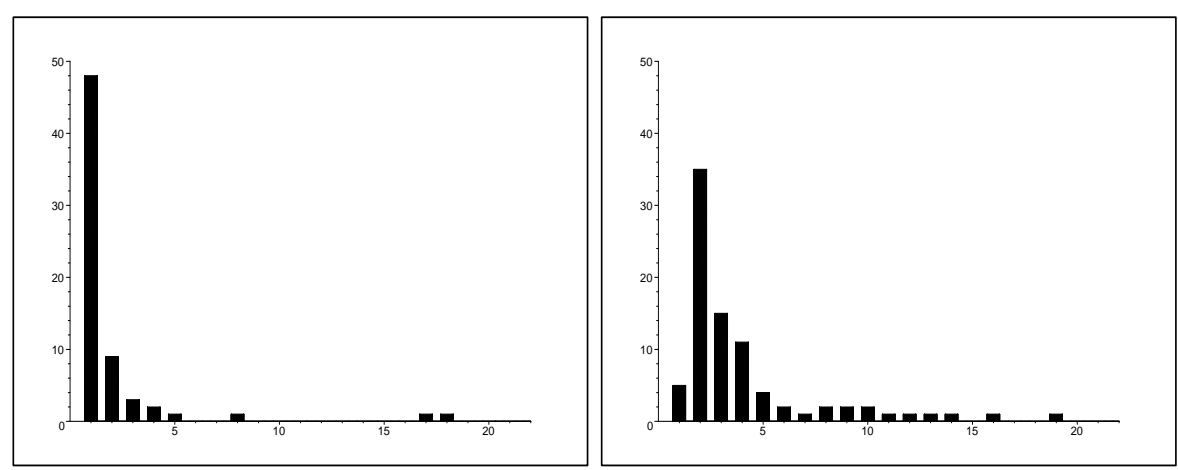

Fig. 5. Realized Lead Time histogram for one week and for two weeks estimated lead time
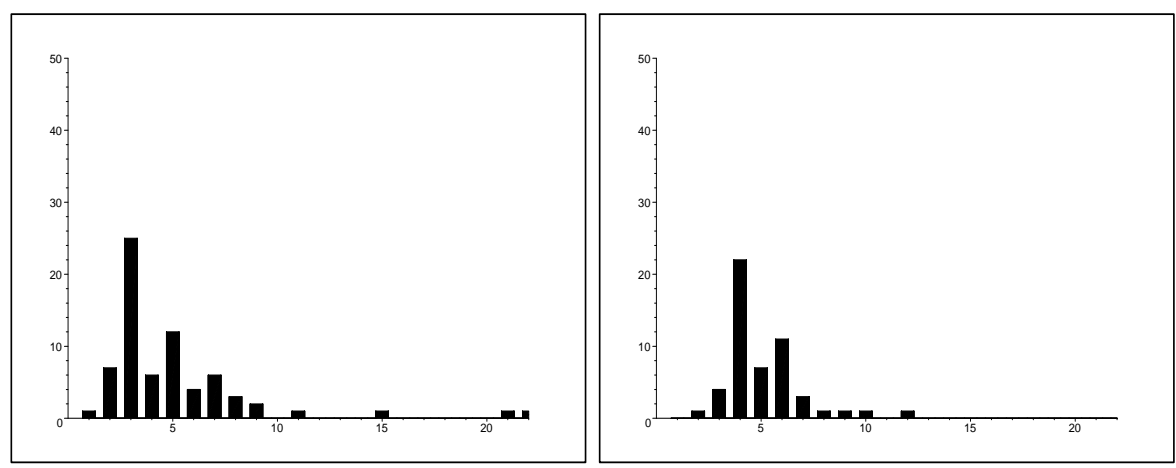

Fig. 6. Realized Lead Time histogram for three weeks and four weeks estimated lead time
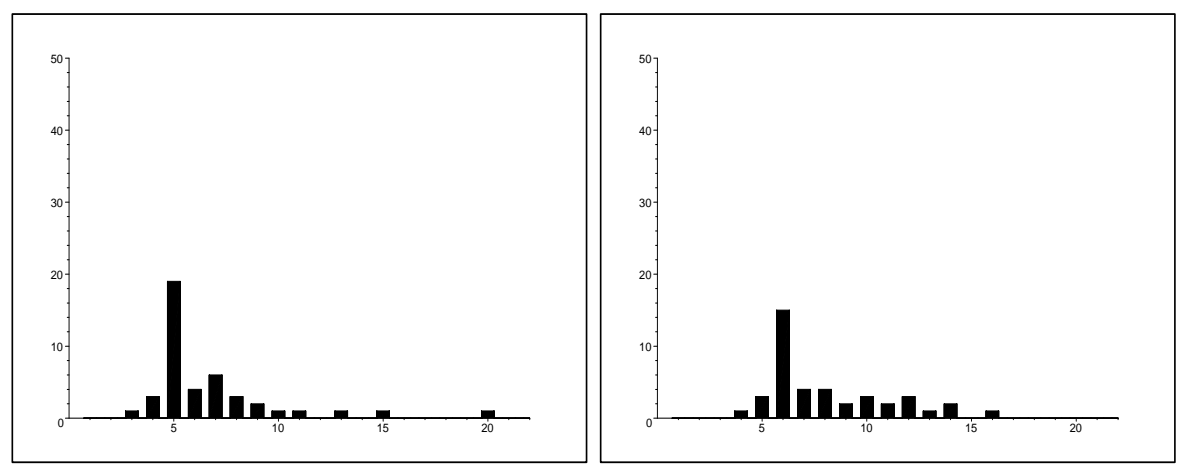

Fig. 7. Realized Lead Time histogram for five weeks and six weeks estimated lead time

the simplest relevant model: first we checked the model with $p=1$ as a good simplifying choice, the interruptions of the engineers being thus neglected. In setting the parameters of this model we used the initial engineers conjectured characteristics of the design tasks, and we estimated the inter-arrival time of new unplanned activities (i.e. $\lambda$ ) from the first data set (i.e. estimated lead time one week).

Given the before-mentioned straightforward relationship between the estimated lead and solving times we assumed that the main reason for a longer estimated lead time for a design task is a larger amount of total number of 

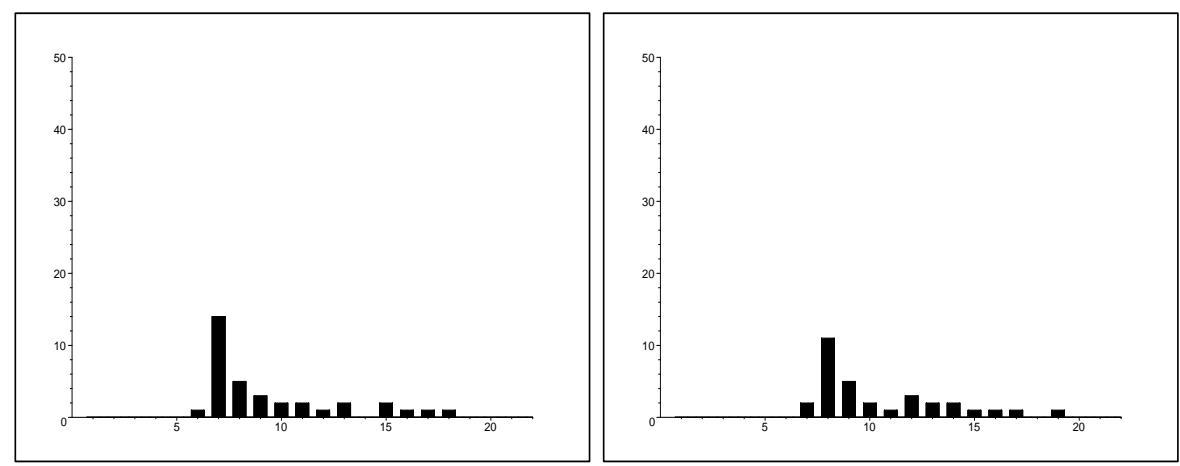

Fig. 8. Realized Lead Time histogram for seven weeks and eight weeks estimated lead time

\begin{tabular}{|l|l|l|l|l|l|}
\hline $\begin{array}{l}\text { Estimated } \\
\text { Lead Time }\end{array}$ & $\begin{array}{l}\text { Sample } \\
\text { size }\end{array}$ & $\begin{array}{l}\text { Model Parameters } \\
\left(N_{a}(n), \mu, \lambda, p\right)\end{array}$ & D-statistic & $\begin{array}{l}\text { K-S } \\
(0.01)\end{array}$ & $\begin{array}{l}\text { K-S } \\
(0.1)\end{array}$ \\
\hline 2 weeks & 85 & $(8,4,1.5,1)$ & .1253 & .1742 & .1307 \\
\hline 3 weeks & 70 & $(12,4,1.5,1)$ & .2335 & .1916 & .1438 \\
\hline 4 weeks & 52 & $(16,4,1.5,1)$ & .3807 & .2217 & .1663 \\
\hline 5 weeks & 43 & $(20,4,1.5,1)$ & .4452 & .2433 & .1825 \\
\hline 6 weeks & 41 & $(24,4,1.5,1)$ & .3122 & .2490 & .1868 \\
\hline 7 weeks & 35 & $(28,4,1.5,1)$ & .3680 & .2686 & .2018 \\
\hline 8 weeks & 32 & $(32,4,1.5,1)$ & .4148 & .2809 & .2108 \\
\hline
\end{tabular}

Table 1

Kolmogorov-Smirnov goodness-of-fit test results — model without re-prioritization

planned activities to be done. Thus, we checked our model using a multiplication of the stochastic planned activities proportional with the number of weeks given by the estimated lead time.

We afterwards tested the model on the other seven data sets. The KolmogorovSmirnov test showed that our model agrees only with the second data group of two weeks (see Table 1).

For the other six groups, the model performed poorly. In view of the occurrence of interruptions of the engineers during the solving of design tasks, this makes sense. We expect that the effect of interruptions on the realized lead time will be better visible for design tasks with larger estimated lead times, than for design tasks with smaller estimated lead times. We therefore concluded that we cannot neglect the effects of interruptions. From the first group we estimated the $\lambda$ value together with the $p$ value, obtaining $p=0.85$. Thus, we have computed the tests again, with $p=0.85$, for the two to eight weeks estimated lead time. Also, since we did not have any information regarding 


\begin{tabular}{|l|l|l|l|l|l|}
\hline $\begin{array}{l}\text { Estimated } \\
\text { Lead Time }\end{array}$ & $\begin{array}{l}\text { Sample } \\
\text { size }\end{array}$ & $\begin{array}{l}\text { Model Parameters } \\
\left(N_{a}(n), \mu, \lambda, p\right)\end{array}$ & D-statistic & $\begin{array}{l}\text { K-S } \\
(0.01)\end{array}$ & $\begin{array}{l}\text { K-S } \\
(0.1)\end{array}$ \\
\hline 2 weeks & 85 & $(8,4,1,0.85)$ & .1678 & .1742 & .1307 \\
\hline 3 weeks & 70 & $(12,4,1,0.85)$ & .1236 & .1916 & .1438 \\
\hline 4 weeks & 52 & $(16,4,1,0.85)$ & .1397 & .2217 & .1663 \\
\hline 5 weeks & 43 & $(20,4,1,0.85)$ & .2792 & .2433 & .1825 \\
\hline 6 weeks & 41 & $(24,4,1,0.85)$ & .1524 & .2490 & .1868 \\
\hline 7 weeks & 35 & $(28,4,1,0.85)$ & .1908 & .2686 & .2018 \\
\hline 8 weeks & 32 & $(32,4,1,0.85)$ & .1996 & .2809 & .2108 \\
\hline
\end{tabular}

Table 2

Kolmogorov-Smirnov goodness-of-fit test results - model with re-prioritization

the average time of interruption activities, we tested the data assuming $\eta=\mu$. This time, the results were much better.

The results of the Kolmogorov-Smirnov goodness-of-fit test show that, in general, we cannot reject the null hypothesis that the empirical distribution is of the form in accord with our model. The D-statistic was less than the critical one (for $\alpha=0.1$ ) for most of the data sets. For the two-week data set we could get an acceptance for a lower $\alpha$, and for the fifth data set the model was rejected. The results are shown in Table 2.

We can explain this slight variation in the acceptance rates $\alpha$, as well as the one rejection by the fact that in each data set there may be design tasks having a longer realized lead time for reasons mentioned in Section 2 other than those incorporated in our model.

However we decided to try to further improve the model since in general, the Kolmogorov-Smirnov test is more sensitive to differences located in the distributions tails, which might be a drawback of our validation method. Indeed, when graphically plotting the distributions which are deemed statistically equivalent by this test, one can still observe differences regarding the skewness and the shift to the right of the probability density functions in the accepted cases (see Figures 9, 10,11), similar to the ones in the rejected case of five weeks (see Figure 12). We considered the above differences to be a systematical error of the model overlooked by the Kolmogorov-Smirnov test, and thus we felt that we needed to improve the model.

To this end, we took into account the discussion at the end of Section 2 about the effects of new high priority design tasks arriving due to the changes in the project network, on the progress of the design tasks already on hand. We 


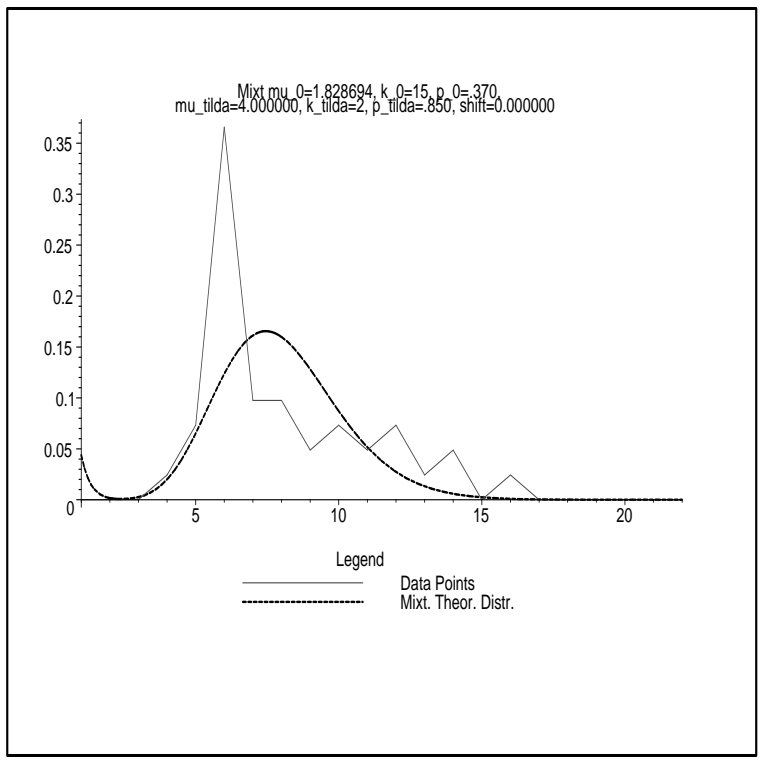

Fig. 9. The p.d.f.'s of the realized lead time and of the estimated one (six weeks)

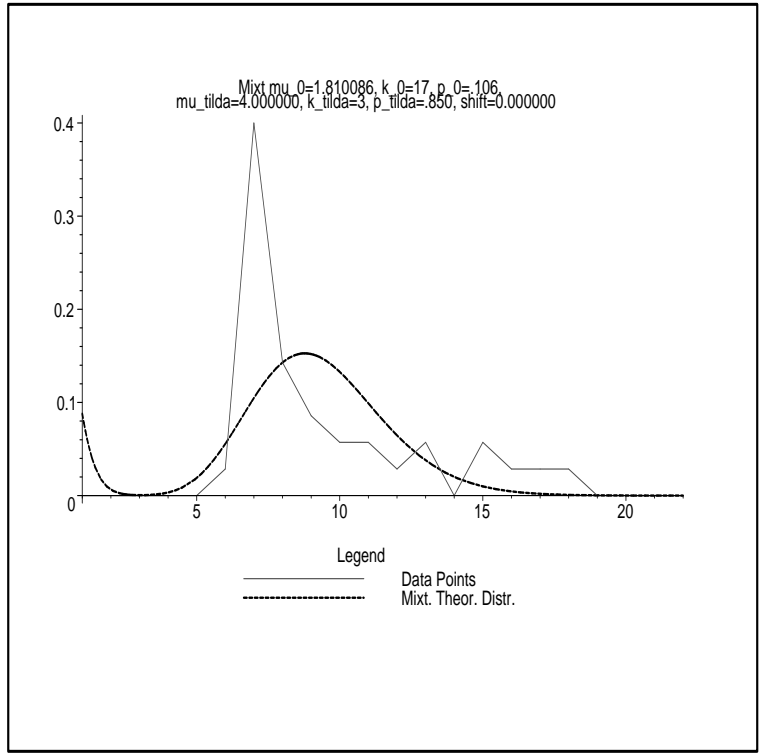

Fig. 10. The p.d.f.'s of the realized lead time and of the estimated one (seven weeks)

assumed that a percentage of the design tasks with an estimated lead time longer than three weeks had their lead time affected by this factor. Therefore, we delayed the distribution given by the model proportionally with the number of weeks given by the estimated lead time. This percentage was obtained by rounding up the average percentage of changes of the NPD project network in the two projects studied in Oorschot et al (2002), and the delay was justified by the inter-arrival rates of new design tasks given by the authors.

The new model was not only accepted in all cases (see Table 3), but also represented a better fit from the probability density function point of view (see Figures 13, 14, 15, 16, 17). Nevertheless, a small difference still remains. 


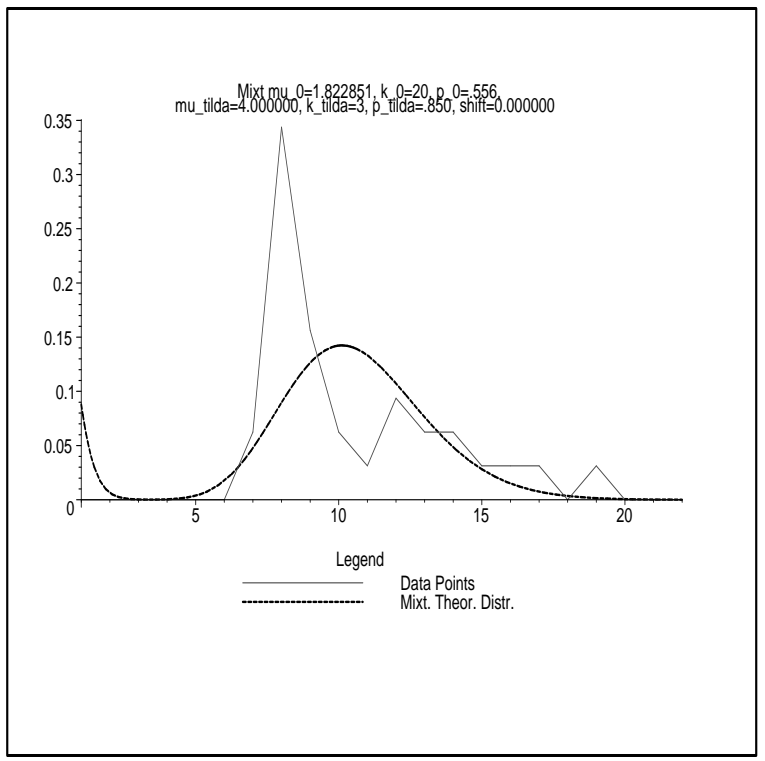

Fig. 11. The p.d.f.'s of the realized lead time and of the estimated one (eight weeks)

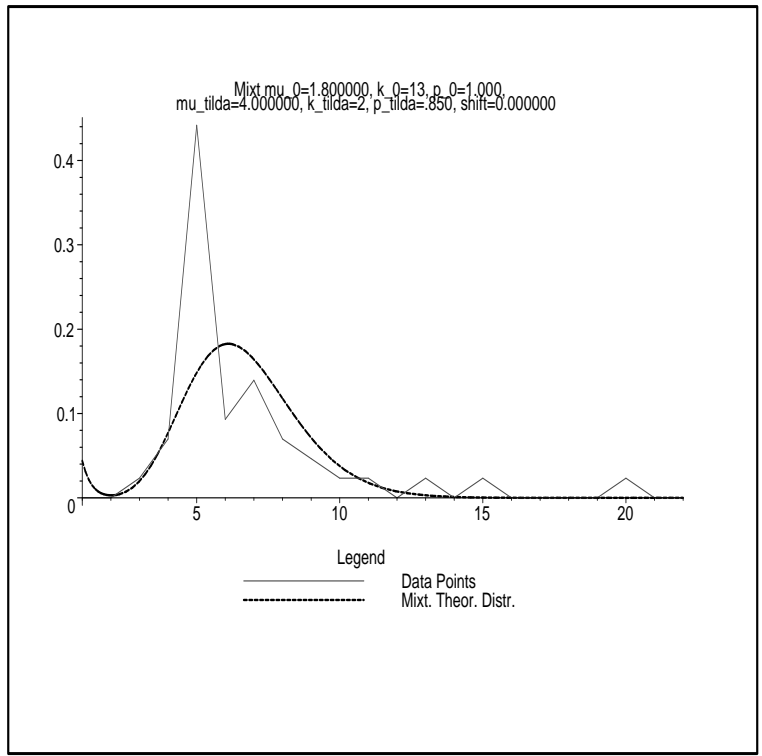

Fig. 12. The p.d.f.'s of the realized lead time and of the estimated one (the rejected case of five weeks)

The reason for it is that we considered all the activities of a design task to be highly uncertain, thus allowing for a non-zero probability for a design task to finish very fast. In real life, however, it is certain that at least a small part of each design task will be usual "routine", thus taking the "usual" time, and hence preventing the design task to finish at an early stage. Although closer to reality, such an information is too task dependent to be easily integrated in a general mathematical model which is also required to be computationally sound.

It is worthwhile to mention that for the estimated lead time of one and two 


\begin{tabular}{|c|c|c|c|c|c|c|}
\hline $\begin{array}{l}\text { Estim. } \\
\text { Lead } \\
\text { Time }\end{array}$ & $\begin{array}{l}\text { Smpl } \\
\text { size }\end{array}$ & $\begin{array}{l}\text { Model Parameters } \\
\left(N_{a}(n), \mu, \lambda, p, \text { delay }\right)\end{array}$ & D-stat. & $\begin{array}{l}\text { K-S } \\
(0.01)\end{array}$ & $\begin{array}{l}\text { K-S } \\
(0.05)\end{array}$ & $\begin{array}{l}\text { K-S } \\
(0.1)\end{array}$ \\
\hline 4 weeks & 52 & $\begin{array}{c}(12,4,1,0.85,1) \\
\text { and } \\
(16,4,1,0.85,-)\end{array}$ & .1446 & .2217 & .1848 & .1663 \\
\hline 5 weeks & 43 & $\begin{array}{c}(12,4,1,0.85,2) \\
\text { and } \\
(20,4,1,0.85,-)\end{array}$ & .2346 & .2433 & .2028 & .1825 \\
\hline 6 weeks & 41 & $\begin{array}{c}(12,4,1,0.85,3) \\
\text { and } \\
(24,4,1,0.85,-)\end{array}$ & .1722 & .2490 & .2076 & .1868 \\
\hline 7 weeks & 35 & $\begin{array}{c}(12,4,1,0.85,4) \\
\text { and } \\
(28,4,1,0.85,-)\end{array}$ & .1925 & .2686 & .2242 & .2018 \\
\hline 8 weeks & 32 & $\begin{array}{c}(12,4,1,0.85,5) \\
\text { and } \\
(32,4,1,0.85,-)\end{array}$ & .2210 & .2809 & .2342 & .2108 \\
\hline
\end{tabular}

Table 3

Kolmogorov-Smirnov goodness-of-fit test results - combined model with reprioritization and delay

weeks we could also set $p=1$, without rejecting the null hypothesis for $\alpha=0.1$. Moreover, for the first three data sets, the application of our model with delay lead to a rejection. This indicates the existence of an interaction between the estimated lead time and the execution process. As a result the average rate of progress for short estimated lead times could be higher than for long estimated lead times, possibly affecting to some extent the negative effect of the urgent new design tasks that might arrive during that short lead time. The psychological literature suggests that people tend to give more priority to urgent design tasks, presumably because time pressure rises and this motivates people to make progress.

Finally, the small imperfections of the fit between the empirical data and the model in Figures 13, 14, 15, 16, 17 reveals an interesting phenomenon that the statistical tests based on the cumulative distribution functions fail to observe. In all the data sets we see that the peak at the estimated lead time is followed by a relative low one for the realized lead time that is one week longer than 


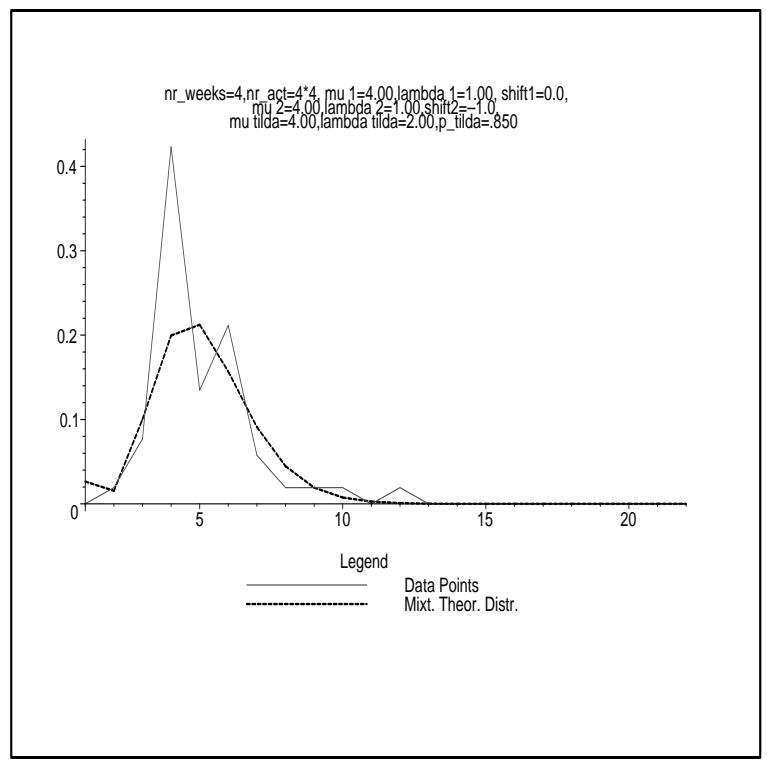

Fig. 13. P.d.f.'s of the realized lead time and of the estimated one (four weeks)

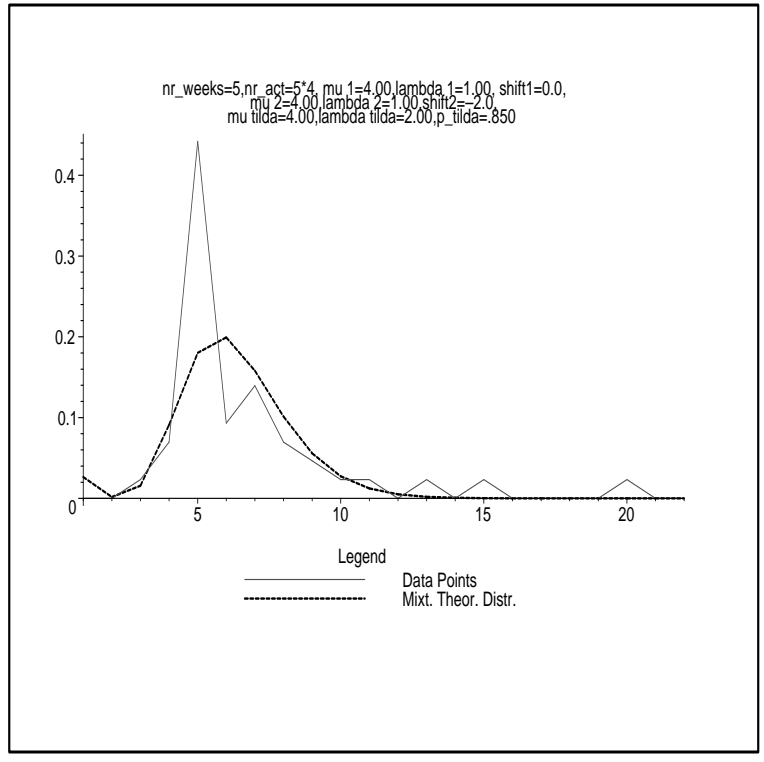

Fig. 14. P.d.f.'s of the realized lead time and of the estimated one (five weeks)

the estimated lead time. This relative law frequency could be attributed to the effect of human behaviour on performance and might be comparable to the well-known hockey-stick phenomenon that can be observed when measuring factory output. This phenomenon refers to the dynamic behavior of output over time, where during the time moment preceding the end of an output measurement interval, the output rises to an extremely high value, after which it decreases to an extremely low value during the start of the next measurement interval. This is generally explained by the inclination of human beings to try to get as much as possible work completed before the end of the measurement period, thereby advancing output that otherwise would have been realized in the next measurement interval. It could be that engineers behave in a similar 


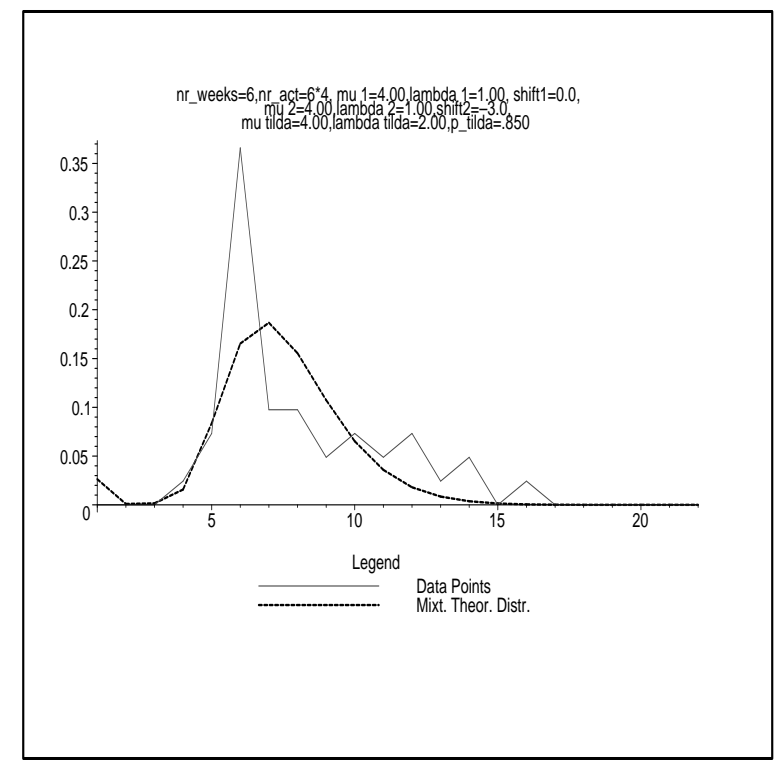

Fig. 15. P.d.f.'s of the realized lead time and of the estimated one (six weeks)

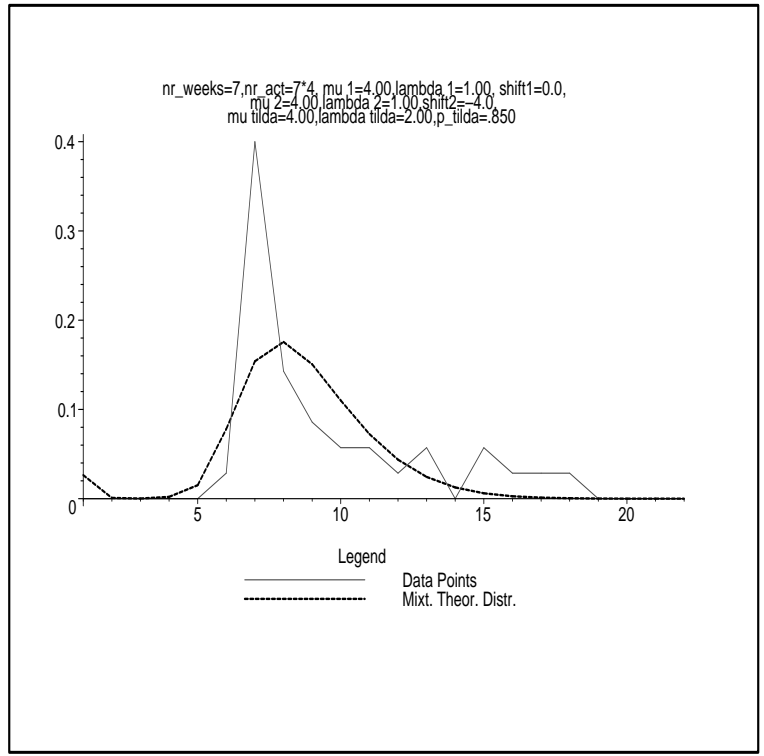

Fig. 16. P.d.f.'s of the realized lead time and of the estimated one (seven weeks)

way and, by looking ahead at the due dates and the work on hand, are able to organize their work such that when the due date approaches, some of the design tasks that log behind less than one week, can still be realized before the due date. For design tasks that log behind more than one week, this may be impossible, or difficult to achieve and thus it is not tried.

Another discussion ought to also be made concerning the uniqueness of the values of $p$. In our model we have considered only one value for $p$, knowing that the larger it is, the less likely the engineers are to interrupt their design tasks. It is however clearly true that in reality some design tasks can be more interconnected than others, thus leading to higher probability of interruption. 


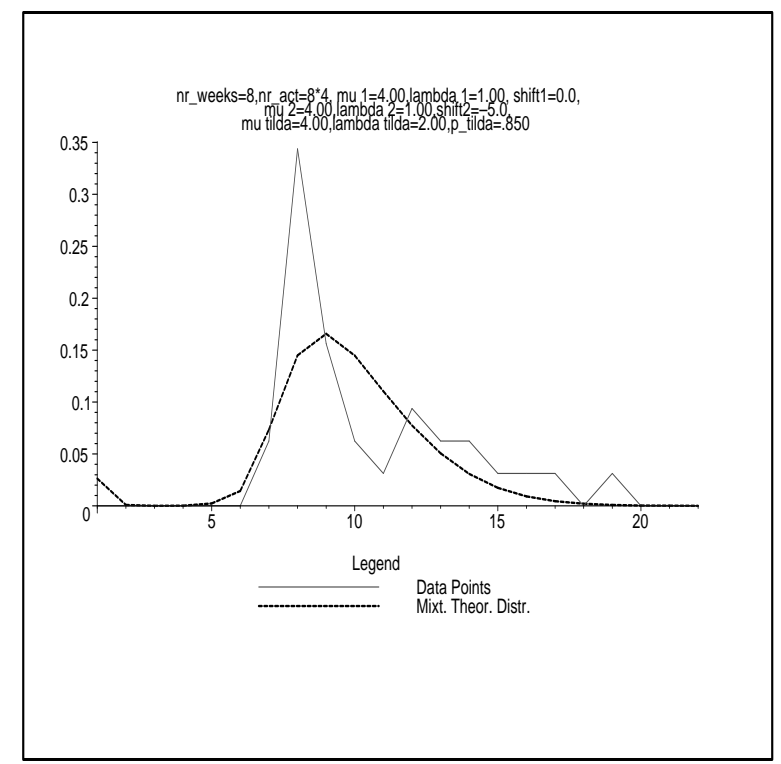

Fig. 17. P.d.f.'s of the realized lead time and of the estimated one (eight weeks)

For instance, a model considering more kinds of design tasks, such as very interconnected - thus with very high probability of interruption (low $p$ ), average interconnected (average $p$ ) and weakly interconnected (high $p$, low interruptibility), would be closer to reality. Unfortunately, specific high quality data is then needed to build and validate such a model, and we have not had at our disposal such datasets, nor have we been aware of any of them available.

\section{Conclusions}

Successful product development requires the understanding of the nature of its constituting design tasks variability. The main contribution of this paper is the derivation of a simple mathematical model which allows the estimation of solving time distribution function for an NPD project design tasks. The model is based on operational characteristics of NPD projects that evolved from theoretical and empirical research on these projects. The structure of the model involves a queuing system for the design tasks to be performed by a team of engineers, but with the possibility of supplemental unexpected activities arrival, as well as with the engineers interrupting themselves from work, with a certain probability, in order to reassess the current priorities of design tasks.

For the first time, to the best of our bibliographical knowledge, such a mathematical model allows for computationally feasible solving time distribution estimation, while at the same time taking into account both design tasks technological uncertainties and human factor characteristics. This is an important feature, because the NPD concept distinguish itself from other more 
classical project management settings also through very high technological uncertainties, stemming from ill-defined and constantly evolving design tasks, thus creating a highly dynamic and challenging environment for the engineers and the managers. Also, the computational feasability entails the possibility of using the model in real-world scalable applications, upon integration in whole NPD control frameworks, as we explain below.

Moreover, in the case of one engineer we asses the validity of our model on real-life NPD data: the Kolmogorov-Smirnov goodness of fit test shows no statistical difference between our model and the data. We discuss these results in detail, and comment upon the possible values of parameters. One important parameter is the interruption probability, and a possibile future work direction can explore different values for it, as soon as new and specific data is collected and becomes available.

Such a model can be a step towards mathematical modelling of NPD, and future work may study ways of integrating it into such frameworks, in general as a way of computing these solving times in order to simplify the overall computations for the NPD control. This integration can be done under various conditions, such as restrictions to the types of design tasks, their precedence relationships, etc.

In a hierarchical NPD control framework from Dragut (2003) this model has been used to compute the transition probabilities a nonstationary Markov decision process. The process determines the performance characteristics of the new product, and optimal control policies have been devised for some of its particular cases. The computational efficiency of the representation model exposed in this paper led to the possibility of obtaining a variety of experimental results, enriching the insights provided by the analytical properties of the optimal policies.

\section{References}

Abate, J., Whitt, W. 1995. Numerical Inversion of Laplace Transforms of Probability Distributions. ORSA Journal on Computing, 7, 36-43.

Aslaksen, E., Belcher, R. 1992. Systems Engineering. Prentice Hall, Inc., Englewood Cliffs, New Jersey.

Best, J.B. 1995. Cognitive Psychology. West Publishing Company, St. Paul, Minneapolis.

Buehler, R.,D. Griffin, M. Ross, 1994. Exploring the "planning fallacy": why people underestimate their task completion times, Journal of Personality and Social Psychology, 67, 366-381.

Dragut, A.B. 2003. A Markovian Approach To The Mathematical Control Of NPD Projects, Technische Universiteit Eindhoven, PhD thesis. 
Eisenhardt, K.M, Tabrizi, B.N., 1995. Accelerating adaptive processes: product innovation in the global computer industry, Administrative Science Quarterly. 1995, 40, 84-110.

Gersick, C.J.G. 1988. Time and transition in work teams:toward a new model of group developmentAcademy of Management Journal,3, 9-41.

Innam, R.R. 1999. Empirical Evaluation of Exponential and Independence assumptions in queuing models of manufacturing systems. Production and Operations Management, 8, 409-432.

Kleinrock, L. 1975. Queuing Systems, vol. 1 Theory. John Wiley and Sons.

McDermott, C. 1999. Managing Radical Product Development in Large Manufacturing Firms: A Longitudinal Study, Journal of Operations Management, 17, 631-644.

Neumann, K., Zimmerman, J. 1999. Heuristic procedures for parallel-machine scheduling problems with stochastic precedence constraints. Annals of Operations Research, 83, 115-136.

Oorschot, van K.E. 2001. Analyzing Radical NPD Projects from an Operational Control Perspective. PhD Thesis, Eindhoven University of Technology, The Netherlands.

Pich, M. T., Loch, C. H., De Meyer, A. 2002, On uncertainty, Ambiguity, and Complexity in Project Management, Management Science, 48, 1008-1023.

Reed, S.K. 1988. Cognition, Theory and Applications. Brooks/Cole Publishing Company, Pacific Grove, California.

Seers, A. and Woodruff, S. 1997. Temporal pacing in task forces:group development or deadline pressure. Journal of Management, 23, 169-187.

Sobek, D. K., Ward, A. C., Liker, J. K, 1999, Toyota's principles of set-based concurrent engineering Sloan Management Revue, 40, 637-683

Shtub, A., Bard, J. F., Globerson, S. Project Management. Engineering, Technology, and Implementation, Prentice Hall. Inc., Englewood Cliffs, New Jersey

Tatikonda, V.M., Rosenthal, S.R. 2000. Technology Novelty, Project Complexity, and Product Development Project Execution Success: A deeper Look at Task Uncertainty. IEEE Transactions on Engineering Management, 47, $74-86$.

Wichers, R. 1996. A theory of individual behavior. Academic Press, London. 